\title{
Is robotic rectal resection the preferred option for resectable cancer?
}

\author{
Hanumant Chouhan ${ }^{1,2}$, James Shin ${ }^{3}$, Seon-Hahn Kim ${ }^{1}$ \\ ${ }^{1}$ Colorectal Division, Department of Surgery, Korea University Anam Hospital, Korea University College of Medicine, Seoul \\ 02841, South Korea. \\ ${ }^{2}$ Department of Colorectal Surgery, Monash Health, Melbourne 3175, Australia. \\ ${ }^{3}$ Nepean Hospital, Kingswood, Sydney 2747, Australia.
}

Correspondence to: Prof. Seon-Hahn Kim, Colorectal Division, Department of Surgery, Korea University Anam Hospital, Korea University College of Medicine, Seoul 02841, South Korea. E-mail: drkimsh@korea.ac.kr

How to cite this article: Chouhan $\mathrm{H}$, Shin J, Kim SH. Is robotic rectal resection the preferred option for resectable cancer? Miniinvasive Surg 2018;2:18. http://dx.doi.org/10.20517/2574-1225.2018.40

Received: 11 Jun 2018 First Decision: 2 Jul 2018 Revised: 16 Jul 2018 Accepted: 17 Jul 2018 Published: 20 Jul 2018

Science Editor: Gordon N. Buchanan Copy Editor: Jun-Yao Li Production Editor: Cai-Hong Wang

\begin{abstract}
The ultimate goal of rectal cancer surgery is to achieve a negative circumferential, distal resection margin and intact mesorectal excision; however, controversy remains as to what is the best approach. Based on the current evidence, open surgery remains the "gold standard", however recent improvements in minimally invasive surgery (MIS) techniques with the introduction of robotic surgery and transanal total mesorectal excision have questioned the historical approach of open rectal dissection. A robotic system (da Vinci) overcomes many of the limitations of laparoscopic surgery. A robotic system is more like an open surgery: it gives a 3-dimensional magnified view, endowrist movements, has a shorter learning curve when compared with laparoscopic surgery, with the added advantage of an MIS procedure. However, the higher cost associated with robotic surgery has limited uptake of this approach in rectal cancer surgery in many parts of world.
\end{abstract}

Keywords: Rectal cancer, open surgery, robotic surgery

\section{INTRODUCTION}

Complete mesorectal excision in the total mesorectal excision (TME) plane, as popularised by Prof. Heald, is the ultimate goal of rectal cancer surgery, as this technique has been shown to reduce local recurrence rates. The controversy, though, lies in defining the best approach to achieve good quality TME. Laparoscopic colorectal resection has been shown to improve postoperative pain, reduce blood loss, reduce the ileus rate, as well as lead to earlier recovery and hospital discharge ${ }^{[1]}$. However, data on oncological outcomes after 
laparoscopic rectal resection has shown no increase in overall or disease-free survival ${ }^{[2-4]}$, and studies have suggested caution in the use of laparoscopic surgery in rectal cancer surgery as it is associated with higher circumferential resection margin (CRM) positive rates, when compared with open surgery ${ }^{[5]}$. Some inherent difficulties with laparoscopic surgery, such as working with rigid straight instruments in a narrow pelvis, 2-dimensional unmagnified views, and poor ergonomics, may have partly affected the oncological outcomes and increased the rates of positive CRM seen with laparoscopic surgery ${ }^{[5]}$.

A robotic platform overcomes some of the limitations of laparoscopic surgery, delivering magnified 3-dimensional views, articulating instruments, offering a stable platform, an extra arm for retraction, and the ability for the surgeon to sit and operate. A meta-analysis comparing laparoscopic surgery with robotic surgery in rectal cancer surgery has shown robotic surgery to be safe, and shown better mesolectal dissection with robotic surgery ${ }^{[6,7]}$. Transanal TME (taTME) is a relatively new approach in rectal cancer resection and the oncological outcome of this approach is yet to be established in rectal cancer surgery. The aim of this review is to investigate the evidence and show that a robotic platform is the best minimally invasive surgery (MIS) approach for rectal cancer surgery.

\section{WHY ROBOTIC SURGERY FOR RECTAL CANCER}

\section{Technical advantages of robotic surgery}

A robotic platform, in comparison with laparoscopic surgery, is more ergonomic, reduces tremors, provides magnified 3-dimensional views, provides an extra working arm and gives the surgeon control of stable camera movements ${ }^{[8]}$. All these advantages surely help surgeons perform a very precise dissection of the TME plane, preserving the autonomic nerves ${ }^{[9]}$. However, due to the loss of haptic feedback with a robotic system, it is relatively easy to cause tissue damage during dissection and traction if not careful. A console surgeon can overcome the tactile feedback limitations of a robotic system by using visual cues, coupled with experience ${ }^{[10]}$.

\section{Questionable safety of laparoscopic rectal dissection}

Laparoscopic surgery has been shown to have improved short-term outcomes including less postoperative pain, reduced ileus rate, early discharge and return to work, however the safety of laparoscopic surgery in rectal cancer surgery is questioned. In a classic trial, laparoscopic surgery was associated with increased CRM positivity rates compared with open surgery (12.4\% vs. 6.3\%). Laparoscopic rectal cancer surgery in particular is associated with a higher conversion rate when compared with colonic laparoscopic resection, and those that are converted to open surgery have a higher mortality rate ${ }^{[5,11]}$. This is a possible reflection of the technical challenges that confront a surgeon during rectal dissection. Recent multicentre randomized controlled trials (RCTs) have shown that the laparoscopic approach may have a higher potential for inferior quality $\mathrm{TME}^{[12]}$, however the long-term data on oncological outcomes are still awaited from these trials.

\section{Potentially better oncological outcomes with robotic rectal surgery}

A multicentre study reported excellent short term oncological outcomes with robotic rectal surgery (97\% 3 -year overall survival $)^{[13]}$. Non-randomised data out of Korea have shown similar results ${ }^{[14]}$. The three-year overall survival is $93.1 \%$, with disease-free survival of $79.2 \%$, a low CRM positivity rate of $5.7 \%$ and a local recurrence rate of 3.6\%: results which are equivalent to laparoscopic surgery from the same group ${ }^{[15]}$. Although long term data on oncological outcomes with robotic rectal surgery are still lacking, better oncological outcomes and the low CRM positivity rates seen with robotic rectal surgery are a possible reflection of better visualisation, and the better ergonomic, stable platform that comes with robotic technology ${ }^{[1,17]}$.

Kim et al. ${ }^{[18]}$ recently reported a trend towards improved overall survival and cancer-specific survival rates with a robotic resection for mid to low rectal cancer (meaning the tumour height from the anal verge was $6.8 \mathrm{~cm}$ ), compared with a laparoscopic resection in a retrospective, propensity score matched analysis (224 patients 


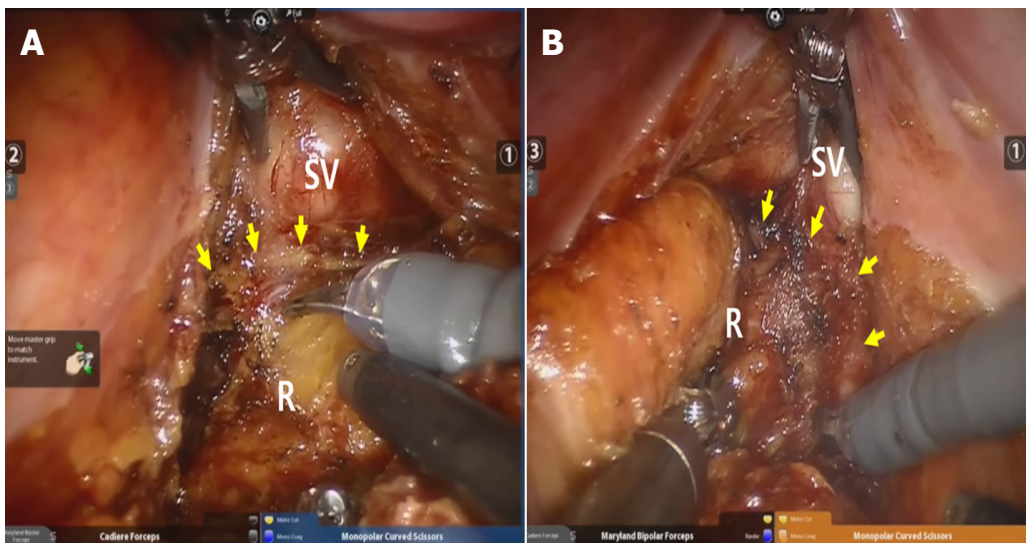

Figure 1. (A) The left neurovascular bundle (arrows) attached to the left seminal vesicle (SV) is dissected from the rectum (R); (B) the right neurovascular bundle (arrows) attached to the right SV is dissected from the R

each). In multivariate analyses, the robotic approach was a significant positive prognostic factor for overall survival and cancer-specific survival $(P=0.0040, \mathrm{HR}=0.333 ; P=0.0161, \mathrm{HR}=0.367)$.

\section{Lower conversion rates with robotic rectal surgery}

As shown in a classic trial, higher conversion rates are associated with poor oncological outcomes and higher mortality. A meta-analysis comparing robotic surgery with laparoscopic surgery found robotic surgery to be associated with a lower conversion rate than open surgery ${ }^{[19]}$, a finding seen in two other studies ${ }^{[20,21]}$. This potentially may allow the surgeon to complete many challenging rectal cancer cases using MIS with similar oncological outcomes. Data from the robotic $v s$. laparoscopic resection for rectal cancer (ROLARR) trial have shown that robotic surgery reduced the conversion rate in obese males with low rectal cancer, a challenging group for laparoscopic surgery ${ }^{[22]}$.

\section{Shorter learning curve with robotic surgery}

The learning curve for laparoscopic colorectal surgery ranges between 30-70 cases $^{[23]}$. A robotic platform which emulated open surgery with the advantage of a 3-dimensional magnified view, using articulating instruments (as compared with the straight instrument in laparoscopy) and better ergonomics has been shown to have a shorter learning curve, at some 20 cases $^{[24,25]}$. However, the loss of haptic feedback with robotic surgery may confound the robotic learning curve. An initial learning period of 30-40 cases and experience in visual cues lead to the second phase, where surgeons start taking on more complex cases.

\section{Better chance for nerve preservation}

Studies comparing sexual dysfunction between laparoscopic surgery and open surgery have shown that sexual function is significantly impaired after laparoscopic surgery ${ }^{[26-28]}$. However, robotic surgery has shown improved post-operative sexual dysfunction and earlier functional recovery, compared with laparoscopic surgery ${ }^{[29]}$. Improved sexual and urinary functions after robotic surgery are reflections of better nerve visualisations using a 3-dimensional magnified robotic platform [Figure 1].

\section{Ability to assess vascularity of anastomosis}

It is well known that distal perfusion is one of the main technical factors that affect the leak rate ${ }^{[30]}$. Measures such as bleeding from marginal vessels, mesenteric vessel pulsation, a lack of distal end discolouration and negative leak tests are all unreliable and do not help predict postoperative leaks ${ }^{[31]}$. Indocyanine green (ICG) which is absorbed near infrared light ${ }^{[32]}$ and detected by a robotic NIR camera system helps assess the distal bowel vascular supply and decrease anastomotic leak ${ }^{[33]}$. In one study, the use of ICG has shown a $60 \%$ reduction in the leak rate ${ }^{[34]}$. It also visualizes unusual vascular anatomy such as the Arc of Riolan ${ }^{[35]}$. Use of 


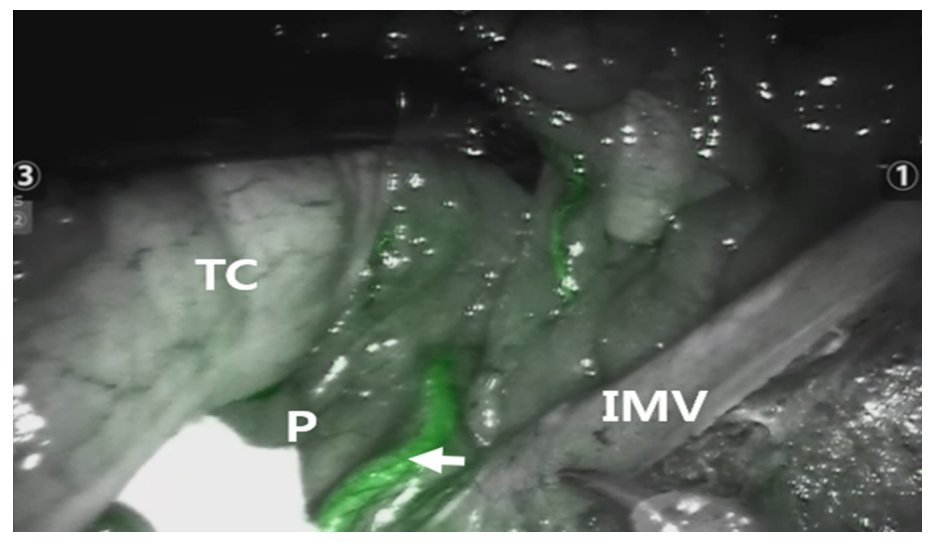

Figure 2. The Arc of Riolan (arrow) is highlighted by indocyanine green fluorescence during a high ligation of the inferior mesenteric vein (IMV) close to the pancreas (P). The transverse colon (TC) is cephalad retracted

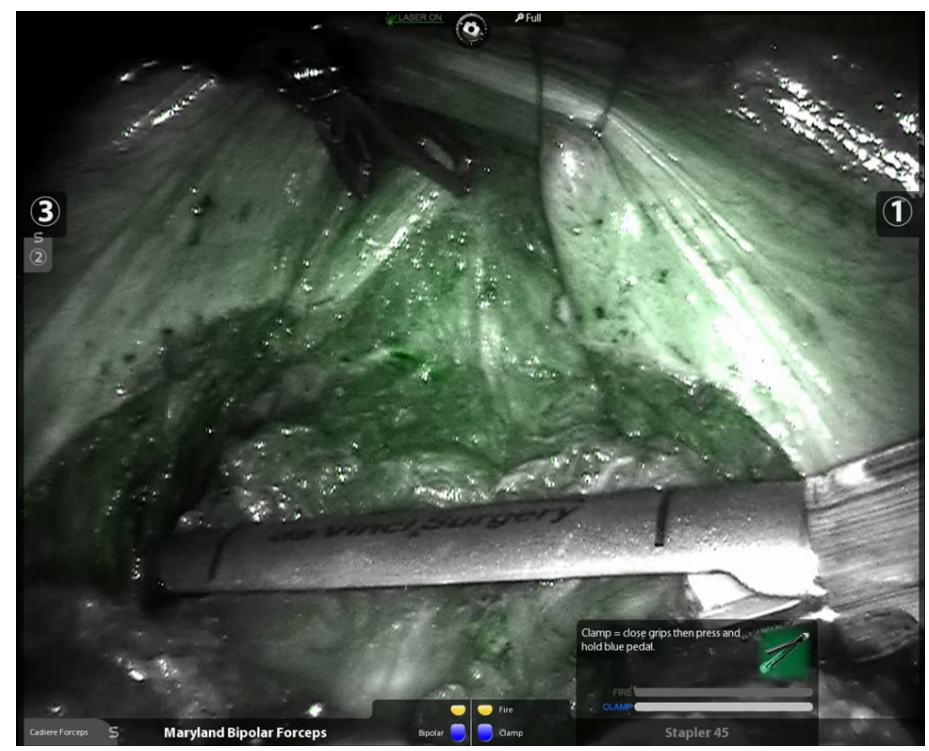

Figure 3. The rectum is transected with guidance of indocyanine green fluorescence to confirm good perfusion on the distal rectal stump

ICG is also gaining popularity in identifying bilateral ureters and positive lateral pelvic lymph nodes during robotic rectal surgery [Figures 2 and 3 ].

The Arc of Riolan can be highlighted by indocyanine green fluorescence during a high ligation of the inferior mesenteric vein close to the pancreas. The transverse colon is cephalad retracted. When the Arc of Riolan exists, it should be preserved for better perfusion to the proximal segment of the anastomosis after rectal resection $^{[35]}$ [Figures 2 and 3].

\section{Ability to perform an advanced MIS procedure robotically}

The optimal surgical approach for a positive lateral pelvic node has yet to be established in rectal surgery. Lateral node dissection is associated with increased blood loss and risk of damage to pelvic nerves, however the safety and feasibility of the robotic approach in pelvic lateral node dissection has been demonstrated ${ }^{[36,37]}$. The ability to perform precise dissection with the stable robotic platform and the use of ICG to identify positive lateral nodes may potentially reduce the morbidity associated with this procedure. 
Studies have shown that precise dissection of the lower rectum, in particular intersphincteric dissection, is associated with better long term functional and oncological outcomes ${ }^{[38,39]}$. The robotic platform allows for a very precise dissection of the lower third of the rectum in the very confined space of the deep pelvis. Precise robotic intersphincteric dissection also potentially reduces the duration of the perineal procedure ${ }^{[40,41]}$.

\section{Transanal TME vs. robotic TME}

Despite advances in surgical management of rectal cancer, and advances in different minimally invasive approaches, achieving negative CRM remains a challenge, particularly in rectal tumours in the lower $1 / 3^{[42]}$. To overcome this, and to avoid higher costs associated with robotic procedures, taTME has emerged as a new technique for performing rectal dissection ${ }^{[43,44]}$. Proponents of taTME believe that this is the best approach for rectal dissection, as this technique offers great access to distal 1/3 rectal dissection, a good view of the pelvic anatomy, the ability to define the distal resection margin and potential for double purse-string anastomosis. A multicentre study comparing robotic TME to taTME has found that high quality TME can be achieved by both robotic and transanal approaches in skilled hands ${ }^{[45]}$. However, long term data on oncological and functional outcomes of taTME are yet to be established.

\section{CONCLUSION}

Robotic rectal cancer surgery is safe and feasible and overcomes some of the shortcomings of laparoscopic surgery. This may be the reason why robotic surgery has better oncological and functional rates, along with lower conversion rates when compared with laparoscopic surgery. However, robotic surgery is yet to be compared with open surgery, "the gold standard of rectal cancer resection". The higher costs associated with robotic surgery have been the major drawback in uptake of robotic surgery worldwide ${ }^{[4]}$. However, new robotic platforms coming out in the future may reduce the cost of robotic surgery. Surgery technology continues to advance in order to overcome the limitation of current surgical practice. Innovation is rapid, but adoption of new technology occurs over time. Further prospective clinical trials will verify the true role of the robot in rectal surgery.

\section{DECLARATIONS}

\section{Authors' contributions}

All authors made substantial contributions to: conception, design, acquisition and drafting the article and revising it critically for important intellectual content; and gave final approval of the version to be published.

\section{Availability of data and materials}

Not applicable.

\section{Financial support and sponsorship}

None.

\section{Conflicts of interest}

All authors declared that there are no conflicts of interest.

\section{Ethical approval and consent to participate}

Not applicable.

\section{Consent for publication}

Not applicable.

\section{Copyright}

(c) The Author(s) 2018. 


\section{REFERENCES}

1. Kim NK, Kim MS, Al-Asari SF. Update and debate issues in surgical treatment of middle and low rectal cancer. J Korean Soc Coloproctol 2012;28:230-40.

2. Laparoscopically assisted colectomy is as safe and effective as open colectomy in people with colon cancer. Abstracted from: Nelson H, Sargent D, Wieand HS, et al; for the Clinical Outcomes of Surgical Therapy Study Group. A comparison of laparoscopically assisted and open colectomy for colon cancer. N Engl J Med 2004; 350: 2050-2059. Cancer Treat Rev 2004;30:707-9.

3. Leung KL, Kwok SP, Lam SC, Lee JF, Yiu RY, Ng SS, Lai PB, Lau WY. Laparoscopic resection of rectosigmoid carcinoma: prospective randomised trial. Lancet 2004;363:1187-92.

4. Milsom JW, Bohm B, Hammerhofer KA, Fazio V, Steiger E, Elson P. A prospective, randomized trial comparing laparoscopic versus conventional techniques in colorectal cancer surgery: a preliminary report. J Am Coll Surg 1998;187:46-54; discussion 55.

5. Guillou PJ, Quirke P, Thorpe H, Walker J, Jayne DG, Smith AM, Heath RM, Brown JM. Short-term endpoints of conventional versus laparoscopic-assisted surgery in patients with colorectal cancer (MRC CLASICC trial): multicentre, randomised controlled trial. Lancet 2005;365:1718-26.

6. Kim SH, Kwak JM. Robotic total mesorectal excision: operative technique and review of the literature. Tech Coloproctol 2013;17 Suppl 1:S47-53.

7. Bianchi PP, Luca F, Petz W, Valvo M, Cenciarelli S, Zuccaro M, Biffi R. The role of the robotic technique in minimally invasive surgery in rectal cancer. Ecancermedicalscience 2013;7:357.

8. Baik SH, Ko YT, Kang CM, Lee WJ, Kim NK, Sohn SK, Chi HS, Cho CH. Robotic tumor-specific mesorectal excision of rectal cancer: short-term outcome of a pilot randomized trial. Surg Endosc 2008;22:1601-8.

9. Baik SH, Lee WJ, Rha KH, Kim NK, Sohn SK, Chi HS, Cho CH, Lee SK, Cheon JH, Ahn JB, Kim WH. Robotic total mesorectal excision for rectal cancer using four robotic arms. Surg Endosc 2008;22:792-7.

10. Baik SH. Robotic colorectal surgery. Yonsei Med J 2008;49:891-6.

11. Rottoli M, Bona S, Rosati R, Elmore U, Bianchi PP, Spinelli A, Bartolucci C, Montorsi M. Laparoscopic rectal resection for cancer: effects of conversion on short-term outcome and survival. Ann Surg Oncol 2009;16:1279-86.

12. Stevenson AR, Solomon MJ, Lumley JW, Hewett P, Clouston AD, Gebski VJ, Davies L, Wilson K, Hague W, Simes J. Effect of laparoscopic-assisted resection vs open resection on pathological outcomes in rectal cancer: the ALaCaRT randomized clinical trial. JAMA 2015;314:1356-63.

13. Pigazzi A, Luca F, Patriti A, Valvo M, Ceccarelli G, Casciola L, Biffi R, Garcia-Aguilar J, Baek JH. Multicentric study on robotic tumor-specific mesorectal excision for the treatment of rectal cancer. Ann Surg Oncol 2010;17:1614-20.

14. Baik SH, Kim NK, Lim DR, Hur H, Min BS, Lee KY. Oncologic outcomes and perioperative clinicopathologic results after robotassisted tumor-specific mesorectal excision for rectal cancer. Ann Surg Oncol 2013;20:2625-32.

15. Baik SH, Gincherman M, Mutch MG, Birnbaum EH, Fleshman JW. Laparoscopic vs open resection for patients with rectal cancer: comparison of perioperative outcomes and long-term survival. Dis Colon Rectum 2011;54:6-14.

16. D’Annibale A, Pernazza G, Monsellato I, Pende V, Lucandri G, Mazzocchi P, Alfano G. Total mesorectal excision: a comparison of oncological and functional outcomes between robotic and laparoscopic surgery for rectal cancer. Surg Endosc 2013;27:1887-95.

17. Baek JH, McKenzie S, Garcia-Aguilar J, Pigazzi A. Oncologic outcomes of robotic-assisted total mesorectal excision for the treatment of rectal cancer. Ann Surg 2010;251:882-6.

18. Kim J, Baek SJ, Kang DW, Roh YE, Lee JW, Kwak HD, Kwak JM, Kim SH. Robotic resection is a good prognostic factor in rectal cancer compared with laparoscopic resection: long-term survival analysis using propensity score matching. Dis Colon Rectum 2017;60:266-73.

19. Memon S, Heriot AG, Murphy DG, Bressel M, Lynch AC. Robotic versus laparoscopic proctectomy for rectal cancer: a meta-analysis. Ann Surg Oncol 2012;19:2095-101.

20. Scarpinata R, Aly EH. Does robotic rectal cancer surgery offer improved early postoperative outcomes? Dis Colon Rectum 2013;56:253-62.

21. Baek SJ, Al-Asari S, Jeong DH, Hur H, Min BS, Baik SH, Kim NK. Robotic versus laparoscopic coloanal anastomosis with or without intersphincteric resection for rectal cancer. Surg Endosc 2013;27:4157-63.

22. University of California, Irvine. RObotic Versus LAparoscopic Resection for Rectal Cancer (ROLARR). ClinicalTrials.gov Identifier: NCT01736072.

23. Kayano H, Okuda J, Tanaka K, Kondo K, Tanigawa N. Evaluation of the learning curve in laparoscopic low anterior resection for rectal cancer. Surg Endosc 2011;25:2972-9.

24. Kim YW, Lee HM, Kim NK, Min BS, Lee KY. The learning curve for robot-assisted total mesorectal excision for rectal cancer. Surg Laparosc Endosc Percutan Tech 2012;22:400-5.

25. Bokhari MB, Patel CB, Ramos-Valadez DI, Ragupathi M, Haas EM. Learning curve for robotic-assisted laparoscopic colorectal surgery. Surg Endosc 2011;25:855-60.

26. Jayne DG, Brown JM, Thorpe H, Walker J, Quirke P, Guillou PJ. Bladder and sexual function following resection for rectal cancer in a randomized clinical trial of laparoscopic versus open technique. Br J Surg 2005;92:1124-32.

27. Sartori CA, Sartori A, Vigna S, Occhipinti R, Baiocchi GL. Urinary and sexual disorders after laparoscopic TME for rectal cancer in males. J Gastrointest Surg 2011;15:637-43.

28. Morino M, Parini U, Allaix ME, Monasterolo G, Brachet Contul R, Garrone C. Male sexual and urinary function after laparoscopic total mesorectal excision. Surg Endosc 2009;23:1233-40. 
29. Kim JY, Kim NK, Lee KY, Hur H, Min BS, Kim JH. A comparative study of voiding and sexual function after total mesorectal excision with autonomic nerve preservation for rectal cancer: laparoscopic versus robotic surgery. Ann Surg Oncol 2012;19:2485-93.

30. Kingham TP, Pachter HL. Colonic anastomotic leak: risk factors, diagnosis, and treatment. J Am Coll Surg 2009;208:269-78.

31. Karliczek A, Harlaar NJ, Zeebregts CJ, Wiggers T, Baas PC, van Dam GM. Surgeons lack predictive accuracy for anastomotic leakage in gastrointestinal surgery. Int J Colorectal Dis 2009;24:569-76.

32. Aziz Aadam A, Wani S, Kahi C, Kaltenbach T, Oh Y, Edmundowicz S, Peng J, Rademaker A, Patel S, Kushnir V, Venu M, Soetikno R, Keswani RN. Physician assessment and management of complex colon polyps: a multicenter video-based survey study. Am J Gastroenterol 2014;109:1312-24.

33. Jafari MD, Lee KH, Halabi WJ, Mills SD, Carmichael JC, Stamos MJ, Pigazzi A. The use of indocyanine green fluorescence to assess anastomotic perfusion during robotic assisted laparoscopic rectal surgery. Surg Endosc 2013;27:3003-8.

34. Bae SU, Baek SJ, Hur H, Baik SH, Kim NK, Min BS. Intraoperative near infrared fluorescence imaging in robotic low anterior resection: three case reports. Yonsei Med J 2013;54:1066-9.

35. Toh JWT, Matthews R, Kim SH. Arc of riolan-preserving splenic flexure takedown during anterior resection: potentially critical to prevent acute anastomotic ischemia. Dis Colon Rectum 2018;61:411-4.

36. Marshall SJ, Hayn MH, Stegemann AP, Agarwal PK, Badani KK, Balbay MD, Dasgupta P, Hemal AK, Hollenbeck BK, Kibel AS, Menon M, Mottrie A, Nepple K, Pattaras JG, Peabody JO, Poulakis V, Pruthi RS, Palou Redorta J, Rha KH, Richstone L, Schanne F, Scherr DS, Siemer S, Stockle M, Wallen EM, Weizer AZ, Wiklund P, Wilson T, Woods M, Guru KA. Impact of surgeon and volume on extended lymphadenectomy at the time of robot-assisted radical cystectomy: results from the International Robotic Cystectomy Consortium (IRCC). BJU Int 2013;111:1075-80.

37. Lee YS, Chong GO, Lee YH, Hong DG, Cho YL, Park IS. Robot-assisted total preservation of the pelvic autonomic nerve with extended systematic lymphadenectomy as part of nerve-sparing radical hysterectomy for cervical cancer. Int J Gynecol Cancer 2013;23:1133-8.

38. Zhang YJ, Yin L, Huang L, Zhang HB, Han Y, Lin MB. Long-term results of intersphincteric resection for low rectal cancer. J Invest Surg 2013;26:217-22.

39. Yamada K, Ogata S, Saiki Y, Fukunaga M, Tsuji Y, Takano M. Long-term results of intersphincteric resection for low rectal cancer. Dis Colon Rectum 2009;52:1065-71.

40. Pigazzi A, Ellenhorn JD, Ballantyne GH, Paz IB. Robotic-assisted laparoscopic low anterior resection with total mesorectal excision for rectal cancer. Surg Endosc 2006;20:1521-5.

41. Park SY, Choi GS, Park JS, Kim HJ, Ryuk JP. Short-term clinical outcome of robot-assisted intersphincteric resection for low rectal cancer: a retrospective comparison with conventional laparoscopy. Surg Endosc 2013;27:48-55.

42. Rickles AS, Dietz DW, Chang GJ, Wexner SD, Berho ME, Remzi FH, Greene FL, Fleshman JW, Abbas MA, Peters W, Noyes K, Monson JR, Fleming FJ. High rate of positive circumferential resection margins following rectal cancer surgery: a call to action. Ann Surg 2015;262:891-8.

43. Kang J, Yoon KJ, Min BS, Hur H, Baik SH, Kim NK, Lee KY. The impact of robotic surgery for mid and low rectal cancer: a casematched analysis of a 3-arm comparison--open, laparoscopic, and robotic surgery. Ann Surg 2013;257:95-101.

44. Wexner SD, Bergamaschi R, Lacy A, Udo J, Brolmann H, Kennedy RH, John H. The current status of robotic pelvic surgery: results of a multinational interdisciplinary consensus conference. Surg Endosc 2009;23:438-43.

45. Lee L, de Lacy B, Gomez Ruiz M, Liberman AS, Albert MR, Monson JRT, Lacy A, Kim SH, Atallah SB. A multicenter matched comparison of transanal and robotic total mesorectal excision for mid and low-rectal adenocarcinoma. Ann Surg 2018; doi: 10.1097/ SLA.0000000000002862.

46. Baek SJ, Kim SH, Cho JS, Shin JW, Kim J. Robotic versus conventional laparoscopic surgery for rectal cancer: a cost analysis from a single institute in Korea. World J Surg 2012;36:2722-9. 